\title{
Polisstudenters avrapportering Perspektiv och verbval i förhör
}

\author{
Av Sofia Ask \& Gunilla Byrman
}

\section{Inledning}

I projektet Texter med tyngd: Skrivande $i$ studier och arbetsliv undersöker vi tre professionsutbildningars språkliga förberedelser för yrkeslivet som poliser, socionomer och lärare. En fråga vi ställer oss är om studenter på ett adekvat vis förbereds inför yrkeslivets skrivande eller om skrivandet $\mathrm{i}$ utbildningar på högskolan enbart är en isolerad färdighet som bara marginellt eller i bästa fall är användbar i yrkeslivet (Ask \& Byrman 2008). Att skriftlig myndighetsutövning sker på ett korrekt sätt är avgörande för att samhället ska fungera och för att medborgarna ska behandlas rättssäkert. Myndighetens utövning innebär att "beslut tas eller åtgärder utförs som uttrycker samhällets maktbefogenheter att bestämma över något i förhållande till medborgarna” (Erdis 2007:38). Sådan myndighetsutövning är lagstadgad i grundlag, förvaltningslag, polislag, socialtjänstlag och skolförordning och är en självklar del i en demokrati. Myndighetsutövning kan vara avgörande för individen, eftersom den på ett fundamentalt sätt kan påverka den enskildes liv. Därigenom har dessa texter tyngd och särskilda krav på att vara rättssäkra och genomskinliga, liksom att de åtgärder som föreslås tydligt ska framgå i texten.

Innehållet och tankarna i denna artikel är delvis en dokumentation av en pilotstudie, och vi diskuterar i det följande enbart polisstudenters texter och den träning de får i skrivande under utbildningen.

I polismyndighetens interna riktlinjer för skrivarbete kommenteras den särställning som Polisens texter har i rättsvårdande syfte:

Inom Polisen produceras stora mängder text av många olika slag. Anmälningar, förhör, beslut och brev är bara några exempel på texttyper som förekommer. Man måste då inse att Polisens rättsvårdande funktion innebär särskilda krav på exakt och tydlig språkbehandling. (Riktlinjer för skrivande inom Polisen 2007:7)

Av citatet ovan framgår att polismyndigheten ställer höga krav på att poliser kan skriva preciserat och begripligt. Det ska i detta sammanhang sägas att skrivsituationen är svår för yrkesverksamma poliser, eftersom de ofta måste referera upprivande händelser alla tider på dygnet. Kommunikationen mellan medborgarna och Polisen rör sig hela tiden mellan talspråk, byråkratspråk och lagspråk, vilket sätter spår i texterna. Dessutom har polisrapporterna, som så småningom kan komma att ingå i förundersökningar (jfr Ask \& Byrman 2010), olika mottagare med varierande krav och förväntningar på texten. Exempelvis ska andra poliser som utreder eller granskar ärendena läsa texterna; det kan också vara åklagare, parter i målet, handläggare på socialförvaltningen eller medier - och alla dessa läser texterna i olika syften. 
Rapporteringen inom Polisen ska på ett sakligt och opartiskt sätt återge det som exempelvis offer, förövare och vittnen har upplevt. För att klara av detta i det kommande arbetslivet måste polisstudenterna få adekvat skrivutbildning och skrivträning. I polisrapporterna kan det vara språkvetenskapligt givande att analysera perspektiv och verbprocesser, eftersom dessa två aspekter i viss mån avslöjar skribentens hållning till det som avhandlas i texten. Indirekt berör detta hur skribenterna uttrycker olika språkhandlingar i sina texter. Nedan diskuterar vi förhörstexter hämtade från en skriftlig avrapportering som polisstudenter gör som övning under sin utbildning.

Som ingång i vår studie har vi läst andra forskares undersökningar om polistexter, som Linda Jönssons (1988) om polisförhör som kommunikationssituation, Birgitta Leijonhielms (1990) om språkliga strukturer i brottsanmälningar, och Ingetora Gumbels (2000) om förhörsprotokoll, där hon visar hur polisens inställning till kvinnomisshandel avspeglar sig i polisförhören och hur detta påverkar protokollens utformning.

\section{Syfte}

Syftet är alltså att diskutera polisers och polisstudenters skrivande generellt och illustrera med två förhörstexter producerade under ett övningspass i utbildningen. Vi inriktar oss på texternas innehåll och på hur detta tar sig språkliga och textstrukturella uttryck. Innehållet i en text studerar vi genom analys av övergripande perspektiv (synsätt) och genom inventering av skribenternas verbval. Vi fokuserar på följande frågor:

- Vad karakteriserar texternas perspektiv?

- Vilka verb framkommer i texterna?

Genom att besvara dessa frågor kan vi få ökad kunskap om texters innehållsstruktur och skribenternas perspektiv på vad de skriver. Vårt antagande är att val av verb hänger samman med vilket övergripande perspektiv som finns i texten. De verb som en skribent använder kan vara avgörande för hur texten uppfattas och vilka relationer som uttrycks, vilket inte är oproblematiskt, eftersom polistexter ska läsas av många olika intressenter som alla har olika förkunskaper, syften med och motiv för att läsa den utredning som texterna ingår i.

\section{Beskrivning av material och metod}

Vi har gjort fältstudier på landets polisutbildningar i Stockholm, Umeå och Växjö för att samla in ett urval av de texter som skrivs inom utbildningen. På så vis kan vi beskriva polisutbildningarnas textgeografi och textkultur, och de aktiviteter som föregår skrivandet där. Sammanlagt består vårt material av 82 fullständiga avrapporteringar från landets tre polisutbildningar, vilket ger cirka 240 kortare texter. ${ }^{1}$ Inom projektet använder vi observation, intervju, enkät och textanalys. ${ }^{2}$

1 Materialet består i sin helhet av observationer av skrivande vid polisutbildningarna och på olika polismyndigheter i landet (Karlskrona, Malmö, Uppsala, Umeå, och Växjö), enkäter med studenter och yrkesverksamma poliser, texter skrivna av polisstudenter och poliser samt intervjuer med verksamma poliser, utredare och åklagare.

2 I denna artikel beskrivs endast delar av textanalysen. 
Polisstudenternas texter föregås av olika simulerade ingripanden. Texterna som vi resonerar om härrör från avrapportering efter övningen "Våld i nära relationer" (observation 200802-24). För att göra övningarna realistiska övar studenterna med skådespelare som agerar offer och förövare. Allt iscensätts så att det ska bli så verklighetstroget som möjligt. Polislärare, ofta en kommissarie eller inspektör, och en beteendevetare eller en psykolog, finns på plats. Alla dessa iakttar studenterna och ger dem råd om hur de ska bete sig mot de inblandade.

Ingripandet ska sedan omvandlas till de skriftliga dokument som lagen kräver i polisärenden. De texter som skrivs efter dessa övningar motsvarar de texter som yrkesverksamma poliser skriver. Polisstudenterna får alltså en ad hoc-träning för det framtida arbetet, men de får nästan bara kommentarer om innehållet i texterna, eftersom IT-lärarna inte är specialutbildade i språk och därför inte har möjligheter att ge kvalificerade språkliga kommentarer (observation 2008-02-25). Detta innebär att studenterna inte får så mycket hjälp med den språkliga utformningen men väl med att skriva in brottsrekvisit i texterna. ${ }^{3}$ En student sade: "Man chansar, får skäll och gör om" (observation 2008-02-25). Det verkar vara ett trial and error-lärande på polisutbildningen, och det finns inga autentiska mönstertexter att tillgå för studenterna, eftersom de anses vara alltför styrande när studenterna själva ska utforma sina texter. Vanligt förekommande texter som alla poliser måste kunna skriva i arbetslivet är anmälan, förhör och avrapporterings-pm. Den sistnämnda är en genre där polisens egna iakttagelser, bedömningar och värderingar står i centrum, och sådana texter skrivs oftast efter varje grövre brott.

Under utbildningen bekantar sig studenterna med de IT-verktyg som de ska använda i sitt kommande yrkesliv, nämligen RAR (Rationell Anmälningsrutin) och DurTvå (Datoriserad utredningsrutin och Tvångsmedelshantering). Dessa två digitalt baserade blankettsystem hjälper på olika sätt polisen att utforma enhetliga, sökbara, kontrollerbara dokument som sedan används av domstolar, sociala myndigheter och andra intressenter.

\section{Teori}

Vi arbetar med text- och diskursanalys (Fairclough 1992, 2001) och utifrån en dialogistisk språksyn som bygger på Bachtin (se vidare Bachtin 1997, Bergh Nestlog 2009). Dessutom studerar vi genredrag hos texterna eftersom dessa är en relevant igenkänningsfaktor. Analyser av olika polistexter görs på tre nivåer. Den textuella nivån tar fasta på språkets formella egenskaper, den relationella berör relationen mellan människor i och utanför texterna och den ideationella behandlar idéinnehållet i texterna.

För att systematiskt beskriva innehållet i texterna använder vi reliefanalys. Reliefteorin (jfr Evensen 2005, Bergh Nestlog 2009) grundar sig på att man kan anlägga olika perspektiv på texter beroende på vad som uppfattas som viktigt och mindre viktigt i dem. Därigenom stiger vissa delar av texten fram i förgrunden - skelettet i texten - och andra träder fram i bakgrunden - köttet på benen.

3 Brottsrekvisit är ett juridiskt samlingsbegrepp för de förutsättningar som måste vara uppfyllda för att ett brott i lagens mening ska föreligga. 
Evensen skriver: 'For å skrive en god tekst er det ikke nok å ha et innhold; vi må også signalisere et gjennomgripende perspektiv på innholdet" (Evensen 2005:191). Aspekterna som framträder i perspektivet "anläggs av skribenten från en given utgångspunkt och synvinkel, och riktas mot en idé som formuleras genom ett meningsskapande. Skribenten förbereder samtidigt texten för läsarens möjlighet att skapa mening och att anlägga perspektiv" (Bergh Nestlog 2009:22). Meningsskapandet ingår i ett socialt sammanhang för både skribent och läsare, och i bästa fall blir det en lyckad dialog. Hur perspektivet framträder kan alltså skilja sig mellan olika läsare och också vid en läsares omläsning av texten (se t.ex. Evensen 2005:201). Både skribent och läsare bär med sig sina föreställningar, som inverkar på texten och tolkningen. Meningsskapandet rör alltså skribenten, läsaren och texten och är en dynamisk process.

Teorin antar också att texter struktureras i enheter och avsnitt. En funktionell textenhet är den minsta enhet som möjliggör för läsaren att skapa mening i en text och som för läsaren har en identifierbar kommunikativ funktion (Bergh Nestlog 2009:26). Vad som ingår i en enskild funktionell textenhet beror på kontexten. Ett funktionellt textavsnitt byggs upp av funktionella textenheter. I definitionen av de båda begreppen ryms ideationella, relationella och textuella aspekter, som berör innehåll, funktion och form. Textavsnitten utgör i korrekt skrivna rapporter egna grafiska stycken.

Lennart Hellspong och Per Ledin beskriver tre viktiga delar i den relationella (interpersonella) strukturen, nämligen språkhandlingar, attityder och ramar (1997:158). Med språkhandling avses de handlingar som bygger upp en text. De grundläggande språkhandlingar som Hellspong och Ledin beskriver är bland andra påståenden, frågor, uppmaningar, interjektioner och utrop (1997:161ff). Det ska påpekas att det inte finns ett ett-till-ett-förhållande mellan språkhandlingar och kommunikativa handlingar. En uppmaning kan döljas i ett påstående ("Det är dyrt med el" kan betyda "Släck lampan!"), och i en fråga kan det gömma sig andra motiv än att söka information ("Sitter du alldeles ensam?" kan betyda "Nu ska jag sätta mig bredvid dig”').

I polistexterna finns olika språkhandlingar, exempelvis "återge", som är en vanlig språkhandling i polistexternas bakgrund. Men möjligheten finns att välja "påstår" om polisen skulle vilja signalera misstro till den misstänktes uttalanden, medan "säger" eller "berättar" signalerar en sakligt neutral inställning till det som avhandlas i texten. Vi antar att språkhandlingar påverkar läsarens uppfattning om skribentens inställning till det som skildras.

Språkhandlingar uttrycks bland annat genom olika verb. Dessa beskrivs av Holmberg \& Karlsson och innehåller 'betydelser som går ut på att något görs, känns, sägs eller finns till" (2006:75). Processverben delas in i fyra grupper:

\begin{tabular}{|c|c|}
\hline materiella (något görs) & Mannen sparkar kvinnan tre gånger i magen. \\
\hline relationella & stark smärta $\mathrm{i}$ armen. \\
\hline mentala $(\mathrm{n}$ & nsam i hemmet. \\
\hline verbala (något sägs & Mannen skriker ofta fula ord till henne. \\
\hline
\end{tabular}


I polistexter kan man tänka sig att de verb som används speglar den förhördes attityder och känslor till det inträffade men i viss mån även skribentens inställning till det skeende han eller hon återger (se vidare Ask \& Byrman 2010).

\section{Analysmetod och analys}

I analysen exemplifierar vi med två övningstexter för att pröva om texternas perspektiv kan öka kunskapen om hur innehållet struktureras i texterna. Vi studerar texterna i avsikt att identifiera texternas relief och mönster i verbbruket. Analysmetodiken är närläsning av texterna, där vi noterar det mest övergripande och framträdande i innehållet som förgrund; denna underbyggs och utvecklas i bakgrunden. Båda måste vara tydliga för läsaren för att en text ska bli fullt begriplig. Läsaren måste för att reliefen i texten ska tydliggöras se "a local point of departure, from which the speaker invites the hearer to follow him or her in developing a topic within a certain perspective. Backgrounding and foregrounding [...] are constitutive of verbalization and sense-making" (Linell 1992:257). För yrkesverksamma poliser gäller att de ska göra troligt att den eller de personer poliserna skriver en anmälan om har begått en brottslig handling. Det är rimligt att anta att det är i bakgrunden det bestäms om texten övertygar sin läsare, eftersom det är i den som rekvisit utreds och utvecklas.

I första exemplet används en förhörstext, där en polisstudent återger en misshandlad kvinnas muntliga redogörelse i skrift. Följande relief blev synlig i analysen, där förgrunden markeras med fetstil och alla verb är understrukna i både förgrund och bakgrund.

\section{Text I: Autentisk utbildningstext}

Bergström har följande redogörelse:

Bergström har under dagen varit på sitt arbete i Växjö. Efter arbetets slut begav sig Bergström till hemmet där hon städade och tog det lugnt. Vid 14.30 hörde Bergström att det bankade på hennes ytterdörr och att någon skrek utanför dörren. Bergström uppfattade att det var hennes fd. pojkvän, Sven Asp, som skrek att han ville "komma in". Bergström öppnade inte dörren då hon känner sig rädd för Asp.

Några minuter senare fick Bergström ett SMS som Bergström hävdar komma från Asp.

\section{Bergström uppvisar SMS ur sin mobiltelefon. Text som följer:}

"Du din djävla subba ska få på truten om du inte öppnar."

Bergström blev rädd men beslöt sig för att öppna dörren för att "lösa detta för gott".

Asp gick in i lägenheten och tog tag i Bergströms högra arm. Asp knuffade därefter Bergström och utdelade ett slag med knuten högerhand varvid Bergström föll bakåt. Bergström uppger att slaget träffade henne över höger öga. Bergström kände smärta.

Bergström ingde därefter till Polisen. (Uppläst och godkänt)

Förgrunden bildar skelettet i händelseutvecklingen från kl. 14.30, då kvinnan kom hem från arbetet, f.d. pojkvännen Asp anländer till hennes bostad, kvinnans rädsla för honom, hans hotfulla SMS, hans misshandel av henne, och hennes smärta. Förgrunden utkristal- 
liserar sig alltså som konstateranden, ett slags exposition, som blir till textuella hållpunkter när ingripandet ska återges skriftligt och tolkas av läsaren. I förgrunden finns brottsrekvisitet som gör att mannen eventuellt så småningom kan åtalas.

I bakgrunden utvecklar, förklarar och specificerar skribenten händelseförloppet och gör därigenom texten trovärdig genom att omtala hur kvinnan städade, tog det lugnt och hur hon därefter släppte in den f.d. pojkvännen i lägenheten. Även kvinnans (Bergströms) handling att ringa till polisen finns där som en förklaring till att polisen ryckte ut. Specificeringar i bakgrunden ökar textens trovärdighet. För att texten ska uppfattas som lättläst och smidig, måste det finnas ett strukturerat samspel mellan förgrund och bakgrund på så sätt att det $\mathrm{i}$ förgrunden mestadels finns rekvisit, utsagor om det inträffade som i lagens mening är kriminella, och i bakgrunden utvecklas, specificeras och förklaras dessa utsagor.

Reliefen blir bland annat synlig i de verb som texten innehåller. Processer realiseras av verbgrupper (jfr Holmberg \& Karlsson 2006). Vårt antagande är att val av verb hänger samman med vilket perspektiv som finns i texten, eftersom valet av verb vägleder läsaren i hur perspektivet ska uppfattas. Därför blir verbprocesserna på olika sätt framträdande i texternas för- och bakgrund. I tabellen nedan presenteras de verb som förekommer i förgrunden.

Tabell 1. Verbprocesser i förgrunden

\begin{tabular}{|c|c|c|c|}
\hline \multirow[t]{2}{*}{ Processtyp } & \multicolumn{3}{|c|}{ Referent } \\
\hline & Misstänkt & |Målsägare & Skribent \\
\hline Materiell & $\begin{array}{l}\text { Bankade } \\
\text { gick in } \\
\text { tog tag i } \\
\text { knuffade } \\
\text { utdelade (ett } \\
\text { slag) } \\
\text { ska få på truten } \\
\text { (av mannen) }\end{array}$ & $\begin{array}{l}\text { öppnade } \\
\text { ringde } \\
\text { fick } \\
\text { öppnar } \\
\text { inträffade } \\
\text { uppvisar } \\
\text { föll }\end{array}$ & - \\
\hline Relationell & - & - & - \\
\hline Mental & vill "komma in" & $\begin{array}{l}\text { hörde } \\
\text { känner sig } \\
\text { (rädd) } \\
\text { blev rädd } \\
\text { kände (smärta) }\end{array}$ & - \\
\hline Verbal & skrek (2 ggr) & & $\begin{array}{l}\text { hävdar } \\
\text { följer } \\
\text { uppger }\end{array}$ \\
\hline
\end{tabular}


I förgrunden dominerar materiella processer, som kan hänföras både till målsägare och misstänkt, vilket är väntat eftersom texten har som uppgift att relatera skeenden, handlingar och händelser. Polisstudenten är synlig i texten genom referatmarkören "hävdar" och "uppger" och i återgivandet av ett hotfullt SMS i citatet: "Du din djävla subba ska få på truten om du inte öppnar". Genom de mentala processer som den misshandlade kvinnan tillskrivs i texten får vi en bild av en rädd kvinna ("känner sig rädd", "blev rädd") och som har ont ("kände smärta").

Eftersom polisstudenten förhör målsägaren i det här exemplet, får vi inte veta något om den misstänktes mentala processer. ${ }^{4}$ Det mest påfallande i texten, som handlar om mänskliga relationer, är att det inte finns några relationella verb i förgrunden. Däremot finns det fyra verbala processer; den ena är "skrek" med två förekomster. Den tillskrivs den misstänkte och hans hot, och de tre övriga processerna tillskrivs målsägaren "hävdar komma från Asp", "uppger" att hon fått ett slag över höger öga och "följer" det i ett sms från pojkvännen.

I bakgrunden, som fördjupar och ger mer information och kött på benen, återfinns följande verbprocesser:

Tabell 2. Verbprocesser i bakgrunden

\begin{tabular}{|l|l|l|l|}
\hline Process & \multicolumn{3}{|c|}{ Referent } \\
\hline & Misstänkt & Målsägare & Skribent \\
\hline Materiell & $\begin{array}{l}\text { begav sig } \\
\text { städade } \\
\text { öppna } \\
\text { ringde }\end{array}$ & - \\
\hline Relationell & $\begin{array}{l}\text { Var (från hen- } \\
\text { nes f.d. pojk- } \\
\text { vän) }\end{array}$ & $\begin{array}{l}\text { ville lösa (detta för gott) } \\
\text { varit (på sitt arbete) }\end{array}$ & - \\
\hline Mental & - & $\begin{array}{l}\text { tog det lugnt } \\
\text { uppfattade } \\
\text { beslöt sig }\end{array}$ & - \\
\hline Verbal & - & - & - \\
\hline
\end{tabular}

I bakgrunden finns materiella processer enbart kopplade till målsägaren: "begav sig", "städade", "öppna" och "ringde". Dessa verbala processer innehåller expansion och förklaringar till rekvisitet, och det som kan betecknas som upptakten till misshandeln. Det är därför av-

4 Förhöret med den misstänkte, som inte återges här, innehåller också främst materiella processer i förgrunden, hotat, misshandlat, framkallat smärta och en verbal process: förnekar. Skribenten tillför dock verbala processer som är viktiga: underrättas (om rätt till försvarare) och delges (misstanke). 
görande för om den misstänkte ska kunna lagföras. I bakgrunden finns några relationella processer som talar om att gärningsmannen "var hennes fd. pojkvän" och att offret "hade varit på sitt arbete" och att hon ville "lösa detta för gott". De mentala processerna återger att målsägaren "tog det lugnt" och "uppfattade" att det var f.d. pojkvännen, den misstänkte som knackade på dörren.

Vi kan konstatera att största delen av textmängden finns i förgrunden och relativt lite i bakgrunden, Frågan vi ställer oss är om detta är ett återkommande drag i polisstudenters texter. Vi vill i den fortsatta studien av studenttexterna undersöka om det förhåller sig så.

\section{Manipulerad text}

Ett problem som framkommer i många texter skrivna av polisstudenter är att de ofta inte har en ändamålsenlig styckeindelning. I stället kan studenterna låta enbart en mening bilda ett eget stycke, som i texten ovan eller på annat sätt inte markerar styckegräns i enlighet med svensk standard. För att pröva hur en text med respektive utan ändamålsenlig styckeindelning påverkar mottagarna manipulerade vi en annan text, som skrevs vid samma övningsingripande som den förra. Resultatet av manipulationen är att första stycket inleds med en kärnmening i förgrunden följt av en specificerande bakgrund. Andra stycket består uteslutande av förgrund med brottsrekvisit. I tredje stycket omsluter förgrunden bakgrunden: ${ }^{5}$

\section{Text II: Utdrag ur manipulerad utbildningstext}

Barbro berättar att hennes sambo Bengt-Göran hade varit på fest natten mellan den 24/225/2-08 när han sedan kom hem så hade han glömt sina nycklar och kunde inte komma in. $[---]$

Han skickade också några hotfulla meddelande, varav de stod "Jag ska slå sönder dig" i ett av dem. Barbro drog ut telefonjacket i lägenheten och gick och lade sig igen. Bengt-Göran gick sedan från trapphuset. Barbro trodde att Bengt-Göran följt med en kompis hem för att sova där. Bengt-Göran kom tillbaka på måndag morgonen vid 9.30 tiden, då gick han direkt och lade sig och sov. När Bengt-Göran sedan vaknade någon timme senare vid 12 tiden så ringde han till sin arbetsplats och sjukskrev sig. Barbro tyckte inte att han skulle sjukanmäla sig, utan att han skulle gå till jobbet.

Det uppstod då en diskussion mellan dem som sedan eskalerade. Till en början så skrek de bara på varandra och det var verbalt otrevligt, Bengt-Göran skrek "din jävla subba" och "jag ska döda dig" sedan knuffade Bengt-Göran till Barbro så hon trillade in i väggen sedan slog han ett kraftigt slag med handen i ansiktet på Barbro. Barbro tror att Bengt-Göran hade sin hand knuten när han slog henne i ansiktet. Barbro berättar att slaget gjorde väldigt ont och att hon blev mycket rädd för BengtGöran. Barbro är svullen vid höger öga och har blånader.

Barbro berättar att det har hänt tidigare att Bengt-Göran har varit våldsam mot henne. Hon berättar att dom i Torsdags 21/2-08 hade haft en diskussion om att Barbro inte tyckte att Bengt-Göran skulle gå ut och dricka så mycket, diskussionen eskalerade

5 I texten är det endast styckeindelningen som är manipulerad. Allt annat har samma ordalydelse och meningsbyggnad som i originalet. 
och Bengt-Göran tog tag i Barbros vänstra arm och slängde ner henne i soffan och skrek '’håll käften". Barbro blev mycket rädd av händelsen och Bengt-Görans uppträdande. Barbro visar att hon har blåmärke på sin vänstra arm som ser ut som att någon tagit tag $\mathrm{i}$ henne.

$[---]$

Vi testade både den autentiska och den manipulerade texten på två rutinerade polislärare, som undervisar polisstudenter i texthantering. Deras uppgift var att ta ställning till vilken textversion som var tydligast och begripligast, den autentiska eller den manipulerade. Den autentiska texten har en annan styckeindelning, där skribenten i stället för att markera styckegräns med blankrad eller indrag enbart börjar på ny rad längst ut till vänster och därigenom producerat så kallade hybridstycken utan tydliga grafiska markörer. Detta är en vanlig grafisk strategi hos uppsatsskrivande elever och studenter (se vidare Strömqvist 1987). Båda lärarna föredrog den manipulerade versionen där styckegränsmarkeringarna är gjorda i enlighet med svensk standard.

Vårt antagande är därför att texten blir mer lättläst och smidig om det finns ett grafiskt strukturerat samspel mellan förgrund och bakgrund med tydligt markerade styckegränser i layouten. Så ser det inte alltid ut i polisstudenternas texter.

\section{Preliminära slutsatser}

Denna pilotundersökning av polisstudenters texter visar att det är polisstudentens uppgift att få med brottsrekvisit som präglar perspektivet och referatet av förhöret. I de undersökta förhörstexterna är det kvinnans, målsägarens, återberättande som är i fokus, och det är till henne som de flesta materiella och mentala processer kan knytas i såväl förgrunden som bakgrunden genom både berättelsen om den misstänktes och målsägarens agerande. Det är företrädesvis i förgrunden som läsaren kan följa händelseförloppets kronologi och i bakgrunden utvecklas förgrunden mer - som i text II - eller mindre - som i text I. Polislärarnas kommentar till text I är att om den varit autentisk hade den fătt kompletteras med ytterligare förhör, annars hade åklagaren inte haft möjlighet att åtala den misstänkte. Orsak till detta - uttryckt i reliefteoretiska termer är att faktaunderlaget i bakgrunden inte är så utvecklat som den borde vara för att skapa tillräckligt underlag för att gå vidare med utredningen. Den slutsats vi drar av detta är att en fyllig och relevant bakgrund med tydlig struktur skapar trovärdighet. Detta borde innebära att de texter som har en bakgrund där läsaren lätt kan följa vad som förevarit också borde få bättre juridisk bärighet än texter med mager och otydlig bakgrund.

Studien antyder också att ett arrangemang där förgrunden grafiskt omsluter bakgrunden tydliggör textens perspektiv och struktur på ett sätt som gör innehållet i texten lättare att uppfatta. Vår slutsats här blir att vill skribenterna öka läsarens förståelse av texten, ska de tydligt markera styckegränserna och inleda och avsluta styckena med formuleringar som framhåller rekvisit.

I text I finns flest materiella processer i både förgrunden och bakgrunden. De mentala processerna refererar nästan uteslutande till den brottsutsatta kvinnan och enbart en gång till den misstänkte gärningsmannen. Det är påfallande få relationella processer i texten med tanke på 
att texten handlar om mänskliga relationer. Vi hade förväntat oss att finna fler verbprocesser av detta slag, eftersom dessa skulle kunna ge en bild av hur parterna känner sig i förhållande till varandra och det våld som förekommit. I stället relateras texterna främst yttre skeenden, medan de inblandades upplevelser och känslor ges mycket liten plats. Att skriva fram dessa i texterna är uppenbarligen något studenterna måste träna på, eftersom de inblandades känslor och upplevelser också är viktiga att redovisa för att texterna ska bli trovärdiga.

I stort innebär polisutbildning en läroprocess där studenternas identitet påverkas och omformas i riktning mot den kommande yrkesidentiteten. Men många polisstudenter ser inte sig själva som skribenter och betraktar sällan skriftspråket som ett medel för yrkesutövning (jfr Ask 2007). Skriftlig rapportering är en stor del av polisens dagliga arbete.

Vår slutsats är att poliser i hög grad har ett skrivande yrke, och ändå visar vårt enkätmaterial att många polisstudenter ser skrivandet som något nödvändigt ont $\mathrm{i}$ sitt kommande yrkesliv. En orsak till detta kan vara att utbildningen brister i att utveckla en aktiv språklig yrkesidentitet hos studenterna. Hos studenter finns det en osäkerhet om vad som förväntas av dem i det framtida yrkeslivet. Textgenrer som anmälan, förhör och PM kräver en tydlig struktur, och det är ett gott argument för att ge språklig skrivundervisning på utbildningen, så att studenterna kan möta polisyrket olika behov av språk- och textbehärskning.

\section{Litteraturförteckning}

Ask, Sofia 2007. Vägar till ett akademiskt skriftspråk. Växjö: Växjö University Press.

Ask, Sofia \& Byrman, Gunilla 2008. Texter med tyngd: Skrivande i utbildning och yrkespraktik (Ansökan till Vetenskapsrådet.) Växjö: Institutionen för humaniora.

Ask, Sofia \& Byrman, Gunilla 2009b. Polis och medmänniska. Instrumentellt skrivande i förundersökningar. Kommande i HumaNetten vårnumret 2010.

Aurelius, Eva Haettner \& Götselius, Thomas (red.) 1997. Genreteori. Lund: Studentlitteratur.

Bergh Nestlog, Ewa 2009. Perspektiv i elevtexter. Skriftligt argumenterande i grundskolans mellanår. Licentiatavhandling i svenska språket. Växjö: Institutionen för humaniora vid Växjö universitet.

Erdis, Mare 2007. Juridik för pedagoger. Lund: Studentlitteratur.

Evensen, Lars Sigfred 2005. Studie 7: Perspektiv på innhold? Relieff i ungdomsskoleelevers eksamensskriving. I: Berge, Kjell Lars, Evensen, Lars Sigfred, m.fl. (red.), Ungdommers skrivekompetanse. Bind II: Norskeksamen som tekst. Oslo: Universitetsforlaget. S. 191-236.

Fairclough, Norman 1992. Discourse and Social Change. London: Polity Press. Fairclough, Norman 2001. Language and Power. Second edition, London: Longman. Gumbel, Ingetora 2000. Hörd angående misshandel: polisens protokoll vid förhör med misshandlade kvinnor och misstänkta män. Stockholm: Stockholms Universitet, Institutionen för nordiska språk.

Hellspong, Lennart \& Ledin, Per 1997. Vägar genom texten. Lund: Studentlitteratur. Holmberg, Per \& Karlsson, Anna-Malin 2006. Grammatik med betydelse. En introduktion till funktionell grammatik. Uppsala: Hallgren \& Fallgren. 
Jönsson, Linda 1988. Polisförhöret som kommunikationssituation. Linköping: Tema Kommunikation.

Leijonhielm, Birgitta 1990. Polisens brottsanmälningar: om polisernas skrivsituation, om användarnas reaktioner på anmälningarna och en analys av språket $i$ anmälningarna: en undersökning. Stockholm: Rikspolisstyrelsen.

Linell, Per 1992. The embeddedness of decontextualization in the contexts of social practices. I: Vold, Astri Heen (red.), The Dialogical Alternative. Towards a Theory of Language and Mind. Oslo: Scandinavian University Press.

Observation från på polisutbildningen $i$ Växjö 2008-02-24 och 2008-02-25. Opublicerat forskningsmaterial.

Riktlinjer för skrivande inom polisen 2007. Reviderad upplaga, Stockholm: Rikspolisstyrelsen.

Strömqvist, Siv 1987. Styckevis och helt: om styckeindelningens roll i skrivprocessen och bruket av nytt stycke i svenska elevuppsatser. Malmö: Liber. 